\title{
Noël 2014: la nouvelle Eve
}

\section{Julia Vecsey}

L'avantage avec mes histoires, c'est que ce sont toujours de bonnes nouvelles. La cuvée 2014 n'échappera pas à la règle: les mauvaises nouvelles font vendre; c'est pourquoi dans les journaux, on ne trouve en général que des informations catastrophiques, car la presse a besoin d'argent. Or le but de cette nouvelle-ci n'est pas de faire du profit, mais bien de vous distraire, donc vous savez déjà qu'elle se terminera bien, CQFD.

Cette histoire commence en 2015. Les catastrophes naturelles se succèdent, mettant la planète bleue à rude épreuve, les glaciers fondent, le niveau des mers monte, c'est la désolation. Nous allons suivre le parcours d'Eve, qui a 20 ans lorsque nous la rencontrons. Pour tenter de fuir les dures réalités, certains se réfugient dans les rêves que procurent les champignons hallucinogènes, l'héroïne ou dans d'autres paradis artificiels; mais c'est un cercle vicieux, car plus on consomme par exemple de la cocaïne, moins on communique, et faute d'échanges entre les hommes, le monde dysfonctionne d'autant plus.

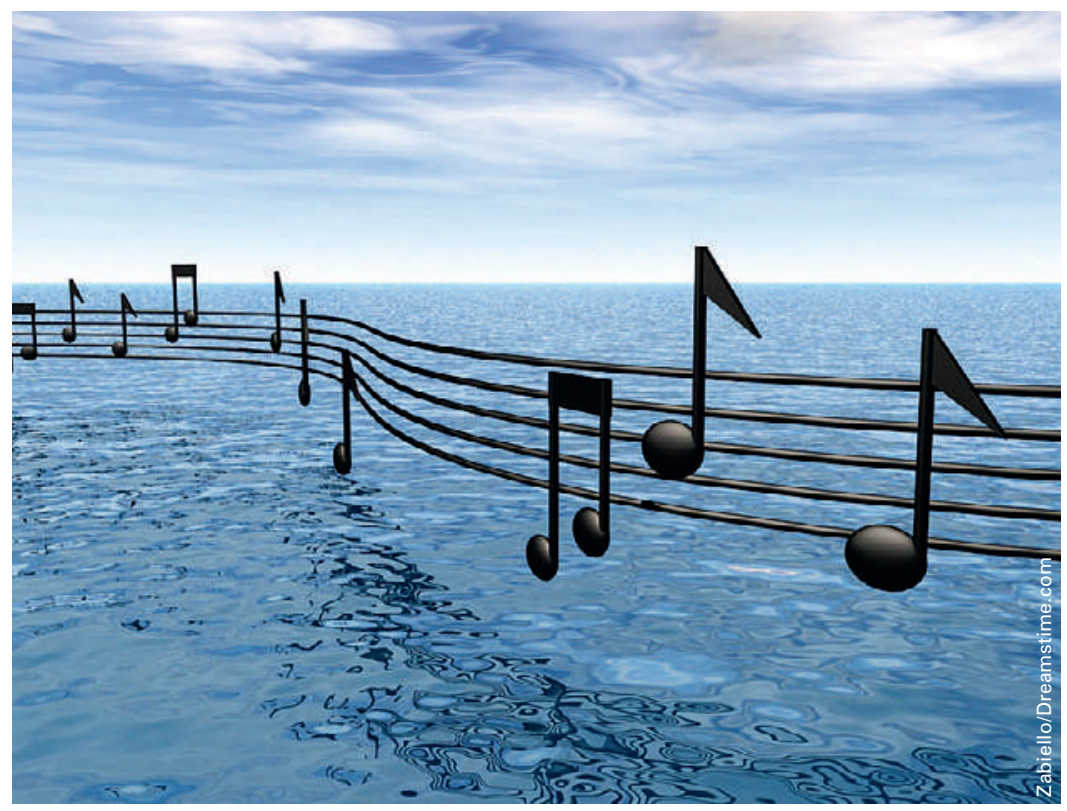

Grâce aux vertus de la mélodie éthérée envolée de sa flûte, Eve échappe à un destin tragique.
Eve, notre héroïne (!), est flûtiste, et son unique préoccupation est de produire des volutes musicales harmonieuses par un travail acharné qu'elle accomplit avec bonheur et volupté.

$\mathrm{Au}$ cours de l'été, alors qu'elle prend des vacances bien méritées en compagnie de sa flûte, au bord de la mer, une catastrophe nucléaire dévaste la terre entière. Les seuls survivants se trouvent être des hydres marines, qui ont la vertu d'être immortelles, et Eve, notre musicienne (je devrais écrire magicienne), qui, grâce aux vertus de la mélodie éthérée envolée de sa flûte, échappe au destin tragique de ses semblables, ravagés par le fléau atomique.

L'explosion nucléaire a provoqué un tsunami responsable de la montée du niveau des mers, inondant les côtes, mais épargnant Eve, emportée au loin par la vague. Les lois de la physique permettent d'expliquer ce miracle: les ultrasons harmoniques de sa mélodie lui ont permis de survivre dans une bulle protectrice semblable à la bulle amniotique originelle, si propice à la propagation des sons. Ne dit-on pas du musicien avant qu'il entre en scène: il est dans sa bulle?

Les hydres qui accompagnent Eve partagent leur univers marin avec des algues produisant de l'oxygène, lui permettant ainsi de respirer et se nourrir.

La mer lui fournit aussi l'occasion de croiser des vers marins aux vertus antiseptiques qui soignent les menues plaies occasionnées par d'éventuels coraux ou par des morsures de serpents aquatiques.

Elle peut ainsi se protéger et prospérer.

Les mois passent, la vie d'Eve se réorganise, elle regagne la terre lasse de son escapade marine obligée, et la solitude commence à lui peser. Elle se demande si d'autres êtres humains ont pu survivre à l'accident dramatique qui est arrivé un peu plus tôt.

Il n'y a pas de hasard, et si un seul autre être humain avait échappé au drame, il fallait qu'ils se rencontrent, ce qui bien sûr est arrivé. Et à Eve de découvrir le prénom de l'autre rescapé: Adam... Vous connaissez la suite... Quand je vous disais que l'histoire finirait bien! Bon d'accord, pour Noël je mélange un peu ancien et nouveau testament, mais c'est pour la bonne cause! 